\title{
Polarity Items in Basque
}

\section{Experimental evidence for their existential reading}

\author{
Urtzi Etxeberria $^{1}$ - Susagna Tubau ${ }^{2} \cdot$ Joan Borràs-Comes ${ }^{3} \cdot$ M.Teresa Espinal ${ }^{3}$
}

Received: 30 January 2020 / Accepted: 31 March 2021 / Published online: 13 April 2021

(c) The Author(s) 2021

\section{Abstract}

This paper presents the results of an experimental investigation that looks into the acceptability and interpretation judgements that Basque native speakers give to sentences with multiple $i$-/bat ere indefinites in declarative sentences. It is argued that Basque $i$-/bat ere indefinites are Polarity Items (PIs) rather than Negative Concord Items (NCIs), as they are consistently associated with an existential reading in unacceptable declarative sentences without an overt negative licensor. That is, Basque $i$-/bat ere indefinites never give rise to a negative interpretation in the absence of an overt negative marker. It is also argued that Basque PIs differ from NCIs in Strict Negative Concord languages such as Greek in relevant ways, thus reinforcing the conclusion that Basque is not a NC language. This study contributes to a better understanding of the conditions that an indefinite expression must meet to be classified as a PI or as an NCI.

Keywords Polarity items - Negative concord items · Basque · Existential reading · Acceptability judgement task - Picture selection task

$凶$ M.T. Espinal

Teresa.Espinal@uab.cat

U. Etxeberria

u.etxeberria@iker.cnrs.fr

S. Tubau

Susagna.Tubau@uab.cat

J. Borràs-Comes

joanborrascomes@gmail.com

1 CNRS-IKER, Campus de la Nive, Château-Neuf 15, place Paul Bert, 64100 Bayonne, France

2 Departament de Filologia Anglesa i de Germanística, Universitat Autònoma de Barcelona, Bellaterra, Cerdanyola del Vallès, Spain

3 Departament de Filologia Catalana, Universitat Autònoma de Barcelona, Bellaterra, Cerdanyola del Vallès, Spain 


\section{Introduction}

In her seminal work on negation in syntax, Laka (1990) contrasted the distribution of negative indefinites in Basque, English and Spanish and postulated a polarity projection $(\Sigma \mathrm{P})$ that c-commands IP in Basque and Spanish but is c-commanded by IP in English (1). She also addressed the nature of some Spanish negative expressions (e.g., nadie 'anybody, nobody') that show a double syntactic behavior: preverbal ones do not require an overt negative marker and behave like a negative quantifier, whereas postverbal ones require it and behave like a Polarity Item (PI), (2). In this paper, we refer to these expressions as Negative Concord Items (NCIs).
a. $E z$ dira denak etorri. not have all-D.PL come

(from Laka 1990:98, ex. (13a))

b. All didn't come.
a. No vino nadie.
not came anybody
b. Nadie vino. nobody came
'Nobody came.'
c. *Vino nadie. came anybody
d. Nadie no vino. nobody not came 'Nobody didn't come.'

From the behavior in (2) Laka postulated that expressions of the sort illustrated by nadie are Negative Polarity Items (NPIs), since the postverbal one needs a negative marker to be licensed: (2a) vs. (2c).

In this paper we investigate the compatibility between two claims made in the literature on Basque, namely (i) that this language has NPIs, since inork in (3a) is not in the domain of an NPI-licensor and thus is ungrammatical (Laka 1990:38); and (ii) that, typologically, Basque is a Negative Concord (NC) language, due to the need for an overt negative marker $e z$ 'not' to negate a sentence, (3b,c) (Etxepare 2003:523). ${ }^{1}$
a. *Inork hori erosi du. anybody that buy AUX
b. Ez du inork hori erosi. not AUX anybody that buy
c. Inork ez du hori erosi. anybody not AUX that buy 'Nobody bought that.'

Under close inspection, though, the above two claims do not appear to be theoretically compatible with one another. A central characteristic of NC is that NCIs can

\footnotetext{
${ }^{1}$ Under this view Basque should be considered a Strict NC language, as stated in Etxeberria et al. (2018), since the presence of the negative marker $e z$ 'not' is obligatory in any negative sentence (as shown in (3)). See Giannakidou (1998) for the distinction between Strict and Non-Strict NC.
} 
give rise to semantic negation in certain contexts (e.g. fragment answers both in Strict and Non-Strict NC languages, and in preverbal position in Non-Strict NC languages), while PIs cannot. Those items that participate in NC have been referred to as 'n-words' (Laka 1990; Vallduví 1994; Déprez 1997; Zanuttini 1989; Espinal 2000, a.o.), (a special kind of) 'strong NPIs' (Giannakidou and Zeijlstra 2017), and more recently 'NCIs' (Déprez et al. 2015; Déprez 2018; Giannakidou 2020). We stick to the latter term for its resemblance to the syntactic relationship these items participate in. By contrast, those items that need to be licensed in specific environments (affective, Klima 1964; (Strawson) downward entailing, Ladusaw 1979; Zwarts 1981 and von Fintel 1999; non-veridical, Zwarts 1995 and Giannakidou 1997, 1998, 2000) are usually named NPIs. We refer to them with the term Polarity Item (PI) (rather than weak NPIs, Giannakidou and Zeijlstra 2017), because-beyond the distribution of licensors and licensees, and the characterization of the environments where these items are licit-our focus in this paper is the syntactic and semantic status of polarity sensitive items not restricted to negative contexts in Basque. ${ }^{2}$

Looking at the data in (2) and (3) it is legitimate to ask what the differences between Spanish nadie and Basque inor are, and to ask more generally what is to be expected from a language that has NCIs and from a language that has PIs. ${ }^{3}$ Therefore, we seek to provide empirical confirmation for the claim that Basque items of the inor type are PIs rather than NCIs, bearing in mind that the former would be a requirement for an existential reading in non-negative contexts, and the latter would be a requirement for Basque to be an NC language. This investigation is part of a more general research topic, namely under which conditions an indefinite expression can be said to behave as a PI or an NCI.

To our knowledge the claim that Basque inor 'anybody' type items are PIs (from now on $i$-indefinites) has been addressed in the literature by considering two sorts of phenomena: (i) whether the co-occurrence of $i$-indefinites and the negative marker $e z$ can give rise to double negation readings, and (ii) whether $i$ - indefinites can occur in fragment answers without a negative marker. The first of these issues was addressed experimentally in Etxeberria et al. (2018) where the acceptability and interpretation of transitive sentences containing $i$ - indefinites in subject and in object position both with and without the negative marker was investigated. The results of this study, in which Basque was compared to two varieties of Spanish (namely Castilian Spanish and the Spanish used in the Basque Country), show that Basque participants judge most items with an overt negative marker with high acceptability ratings, and most items without it with low acceptability ratings, and furthermore that in Basque single negation is the preferred interpretation both in sentences with and without an overt

${ }^{2}$ PIs are distinct from Positive Polarity Items, which are anti-licensed by negation.

(i) a. Ikasleren bat etorri da. student.GEN one come AUX 'Some student came.'

b. $* E z$ da ikasleren bat etorri. not AUX student.GEN one come

${ }^{3}$ We do not exclude the possibility that a language may have both classes of units, a topic to which we will come back in the Discussion section. 
negative marker (with two $i$ - indefinites). In Spanish, by contrast, sentences with low acceptability ratings are interpreted at chance (between single negation and double negation) in both varieties. Etxeberria et al. (2018) show that in Basque double negation readings are not available when two or more $i$-indefinites co-occur with the sentential negative marker within a single sentence, (4), unlike what is claimed in Etxepare (2003:554).
Inork
ez du ezer
inon erosi.
anybody.ERG not AUX anything.ABS anywhere buy
'Nobody bought anything anywhere.'
IT CANNOT MEAN: 'Everybody bought something somewhere.'

The second issue is that $i$-indefinites appear to need the presence of an independent negative marker in fragment answers (Etxepare 2003:547), thus showing that inor in (5Ab) is not an NCI. ${ }^{4}$ The example in (6A) shows that Spanish nadie is well-formed in fragments and conveys a negative reading.
Q: Nor etorri da? who come AUX 'Who came?'
A: a. Inor ez. anybody not 'Nobody.'
b. *Inor. anybody

Although it may seem that the nature of Basque $i$ - indefinites is settled with this test and with further information found in descriptive studies, we aimed to provide experimental confirmation for the PI status of these items beyond fragment answers. Theoretically, there has been a long controversy in the literature with respect to whether NCIs are universal quantifiers, both negative (Zanuttini 1991; Haegeman and Zanuttini 1991, among others) and non-negative (Giannakidou 2000); negative polarity items (Bosque 1980; Laka 1990, among others); and indefinites, both negative (Suñer 1995) and non-negative (Ladusaw 1992, 1994; Zeijlstra 2004; Tubau 2008). Other accounts associate NCIs with numerals of cardinality zero (Déprez 1997, 2000; Espinal 2000), with underspecified quantificational force. Still, some studies attribute an ambiguity to NCIs, either lexical (Martins 2000; Herburger 2001; Espinal and Tubau 2016) or structural (Déprez 1997, 2000, 2011; Déprez and Martineau 2004). What is important for our current purposes is that if Basque $i$ - indefinites are PIs, they are

\footnotetext{
${ }^{4}$ Giannakidou (2006) provides a semantic and a syntactic criterion for the identification of an NCI:
}

\section{An expression $\alpha$ is an NCI iff:}

a. $\quad \alpha$ can be used in structures containing sentential negation or another $\alpha$-expression yielding a reading equivalent to one logical negation; and

b. $\quad \alpha$ can provide a negative fragment answer.

In contrast to (5), it appears to be the case that young generations of Basque are beginning to use indefinites of the inor type as fragment answers without the presence of the negative marker (M. Uribe-Etxebarria, p.c.), a situation that reveals an ongoing change in the language. In this paper we do not deal with fragment answers. See fn. 9. 
expected to contribute an existential reading to the sentence in declarative affirmative sentences, as PIs cannot possibly give rise to semantic negation by themselves. By contrast, if they are NCIs, they will have the potential to contribute a negative reading when not overtly licensed by a negative marker. In this paper this prediction is tested experimentally.

In Sect. 2 we first point out the different word order of affirmative and negative declarative sentences in Basque (Laka 1990; de Rijk 1996; Elordieta 2001; Etxepare and Uribe-Etxebarria 2008, a.o.), and we then provide novel data that illustrate the distribution and meaning of $i$ - indefinites in contrast to other indefinite expressions in this language. In Sect. 3 we present an experimental study that was designed to confirm/test the PI status of Basque $i$ - indefinites, by examining Basque native speakers' acceptability and interpretation judgements of declarative sentences in which indefinites of different complexity occur in subject and in object position. Section 4 presents the results of this investigation, and Sect. 5 discusses the relevance of these results in relation to the initial hypothesis that $i$-indefinites are PIs, but not NCIs. It also discusses the contribution of this study to the more general research topic on the conditions under which an indefinite expression can be said to behave as one type of expression (PI) or the other (NCI), and what is to be expected from a language that only has PIs, and from a language that has both. This section also concludes the paper.

\section{Negative sentences and PIs in Basque}

Most descriptive, as well as generative, grammatical studies identify SOV as the 'neutral' or basic word order of Basque (see de Rijk 1969, a.o.). In addition, in Standard Basque the lexical verb has to precede the auxiliary verb in declarative affirmative sentences (i.e., SOVAUX). See (7). ${ }^{5}$
a. Mutiko-a-k opari bat erosi du.
boy-D.SG.ERG present one.ABS buy AUX
'The boy bought a present.'
b. *Mutiko-a-k opari bat du erosi. boy-D.SG.ERG present one.ABS AUX buy

In negative sentences the auxiliary raises to the position following the negation (i.e., $\mathrm{S} e z$ AUX OV), while leaving the lexical main verb in situ. This is illustrated in (8a). In Basque the presence of an overt negative sentential marker is uniformly required for negative dependencies (Laka 1990; Etxepare 2003; de Rijk 2008; Etxeberria et al. 2018).

a. Mutiko-a-k ez du opari bat erosi. boy-D.SG.ERG not AUX present one.ABS buy

'The boy did not buy a present.'

\footnotetext{
${ }^{5}$ Note that Basque conforms to some of the generalizations about SOV languages stated in the typological literature (e.g., it has postpositions, the auxiliary follows the main verb, and the complementizer follows the subordinate clause). Note also that ( $7 \mathrm{~b}$ ) is considered ungrammatical, except in the Navarro-Labourdin Basque dialect, where constructions of this type have been argued to be 'marked' focus structures, similar to cleft sentences, strongly presuppositional and exhaustive (Duguine and Irurtzun 2010).
} 

b. *Mutiko-a-k
ez opari bat
erosi du.
boy-D.SG.ERG not present one.ABS buy AUX

In declarative affirmative sentences existential indefinites of the norbait 'someone' type are freely allowed.
(9) Norbaitek deitu du.
someone.ERG call AUX
'Someone called.'

However, in negative sentences $i$ - indefinites of the sort exemplified by inor 'anyone' must be chosen. ${ }^{6}$

$$
\begin{aligned}
& E z \text { du inork / *norbaitek deitu. } \\
& \text { not AUX inor.ERG / someone.ERG call } \\
& \text { 'Nobody called.' }
\end{aligned}
$$

In addition, Basque has a series of scalar PIs of the form $N$ bakar bat ere 'lit. $\mathrm{N}$ single one even. ${ }^{7}$ These items have exactly the same syntactic distribution as $i$-indefinites, but have a more complex internal syntax and can combine with partitive nominal complements, as illustrated in (11b). This example shows that the sentential negative marker can license multiple bat ere indefinites while conveying one single negation, exactly like $i$ - indefinites in (4).

\section{a. Ez du ikasle bakar batek ere deitu. not AUX student single one.ERG even call 'Not even a single student called.'}

b. Mutikoetako bakar batek ere ez du pilotetako bakarbat boy-D.pl-GEN single one.ERG even not AUX ball-D.PL.GEN single one ere jo. even hit 'None of the boys hit any of the balls.'

Bat ere indefinites, just like $i$ - indefinites, cannot form a negative sentence by themselves, as illustrated in (3a) above for $i$ - indefinites, and cannot be used in isolation as fragment answers (5Ab). This is exemplified in (12) and (13Ab) respectively.

\section{*Ikasle bakar batek ere hori erosi du.} student single one.ERG even that buy AUX

\footnotetext{
${ }^{6}$ Basque $i$ - indefinites are morphologically built with wh-words to which the prefix $e$ - (possibly related to the negative marker $e z,>i$ - by dissimilation) is added (Michelena 1985; Laka 1990; Euskaltzaindia 1993; Etxepare 2003; de Rijk 2008).
}

(i)
b. $e$-zer prefix $e$-what 'anything'
c. $i$-noiz prefix $i$ - when 'any time'
d. i-non prefix $i$ - where 'anywhere'

${ }^{7}$ Ere can convey the meanings of 'also' or 'even' in English, and the choice between these two readings depends on the position the focal intonation, i.e., the nuclear stress, is placed (Etxeberria and Irurtzun 2015). 


Q:
Nor etorri da?
who come AuX
'Who came?'

A: a. Ikasle bakar bat ere ez. student single one.ERG even not 'Not even a single student.'

b. *Ikasle bakar bat ere. student single one.ERG even

Beyond negative environments, $i$-/bat ere indefinites can also be licensed in a variety of other polarity contexts. As shown in the literature (de Rijk 1972, 1996; Etxepare 2003:547-9) $i$ - indefinites (and bat ere indefinites for the matter) can occur in the protasis of conditionals, yes/no questions, rhetorical questions and second term of comparatives. They can also be licensed in before-clauses and without-clauses, as well as in the complement position of negative predicates and affective predicates, and in a relative clause that restricts the scope of a universal quantifier, among others. But, crucially, $i$-/bat ere indefinites are excluded from pure declarative sentences that do not introduce any of these potential licensors, (3a) and (12). (14) illustrates that sequences with multiple $i$-/bat ere indefinites and no licensor are also ungrammatical (cf. examples in (4) and (11b)).

a. *Inork du ezer jan.

anyone.ERG AUX anything eat

Single Negation: 'No one ate anything.'

b. *Ehiztarietako bakar batek ere du txorietako bakar hunter-D.PL.GEN single one.ERG even AUX bird-D.PL-GEN single bat ere ehizatu. one.ABS even hunt

Single Negation: 'None of the hunters hunted any of the birds.'

However, these examples pose the interesting question of how $i$-/bat ere indefinites are interpreted by native speakers of the language. ${ }^{8}$ In Etxeberria et al. (2018) it is shown that the absence of an overt negative marker in examples such as (14) led Basque participants to rate the sentence as unacceptable. These authors hypothesize that the word order of negative sentences (i.e., S (ez) AUXOV) might be sufficient to assign a single negation interpretation to those sequences, even in the absence of any overt c-commanding licensor in the syntactic structure (Vasishth et al. 2008). In other words, this result is interpreted as suggesting the activation of a repair strategy influenced by the canonical word order of negative sentences in Basque.

An optimal environment to further confirm the validity of the hypothesis that Basque $i$-lbat ere indefinites are PIs is to look at the interpretation that native speak-

\footnotetext{
${ }^{8}$ In relation to this issue, although the study of ungrammatical sentences (and their interpretations) has been neglected by most linguistic theories, there is much work in psycholinguistics that investigates how comprehenders can associate an interpretation with an ungrammatical sentence (Shanon 1973; Frazier and Clifton 2011; Gibson et al. 2013; Atkinson et al. 2016; Beltrama and Xiang 2016, a.o.). Also relevant are those studies that deal with the perception and comprehension of grammatical illusions, among them illusory NPI licensing (Phillips et al. 2011; Parker and Phillips 2016; Muller and Phillips 2020; Wellwood et al. 2018, a.o.). See Giannakidou and Etxeberria (2018) for a review of the ERP literature on NPI licensing, and Panizza and Romoli (2013) for an ERP analysis of Italian mai. More recent experimental work on the processing and neurophysiology of negation include Pablos et al. (2019), Grodzinsky et al. (2020a, 2020b), and Christensen (2020).
} 
ers give to affirmative sentences with multiple $i$-/bat ere indefinites. If Basque has PIs (but does not have NCIs), two outcomes are expected to be observed: (i) PIs without an overt licensor $e z$ 'not' should give rise to low acceptability ratings (thus confirming Etxeberria et al.'s 2018 results); and (ii) PIs without an overt negative licensor $e z$ 'not' should give rise to existential non-negative readings in sequences with the default order of declarative affirmative sentences (i.e., SOVAUX).

By contrast, if Basque has NCIs a different behavior is expected. NCIs have been argued in the literature to carry a syntactic feature ([uNeg], Zeijlstra 2004, and ff.) that probes for a goal with a matching interpretable feature with which to Agree. In contexts where the goal (i.e., an anti-morphic operator) is not overt, the $[u \mathrm{Neg}]$ feature can trigger the insertion of an abstract negative operator as a Last Resort operation. Hence, the interpretation of unlicensed NCIs is predicted to be negative in this approach to NCIs. Conversely, the interpretation of unlicensed PIs is predicted to be purely existential, as these elements are of a non-negative nature. If it were the case that Basque speakers consistently interpreted affirmative sentences with multiple $i$ Ibat ere indefinites and no overt negative licensor as non-negative, we would confirm that Basque $i$-/bat ere indefinites cannot be NCIs and, consequently, that Basque is not a NC language.

In the following section we present an experiment that tested the acceptability and the interpretation that Basque speakers assign to transitive sentences containing two $i$-/bat ere indefinites - one in subject position and the other in object position-in declarative sentences with an overt negative licensor and the word order of a negative sentence on the one hand, and in declarative sentences with no licensor and the word order of an affirmative sentence on the other. Our purpose is to empirically support the prediction that Basque $i$-/bat ere indefinites without a negative licensor should be found unacceptable, and investigate whether they are consistently interpreted-as predicted-as non-negative.

\section{Experiment}

\subsection{Method}

We designed an experiment which consisted of two tasks: (i) an acceptability judgement task, and (ii) a picture selection task (Schütze and Sprouse 2013; Ionin and Zyzik 2014; Tonhauser and Matthewson 2015; Juzek 2016). In the first task, participants were presented with a sentence with no preceding context and had to judge its well-formedness on a 5-point Likert Scale after reading the following instruction: "Read the sentence and decide how good it is for a speaker of Basque on a scale from 1 to 5." In this gradient scale score 1 corresponded to "least acceptable" and score 5 to "most acceptable." Immediately after reporting their perception of the acceptability of a given sentence, participants were directed to the second task on a different slide, where they were presented with the same sentence on top of two pictures and had to choose which of them best represented its meaning. In one picture, none of the characters were performing/had performed an action (this picture would correspond to a negative reading); in the other picture only one of the characters was performing/had 
40. Irakur ezazu esaldia, eta aukeratu zein irudik deskribatzen duen hoberen esaldiak dioena.

Inork ezer eraikitzen du
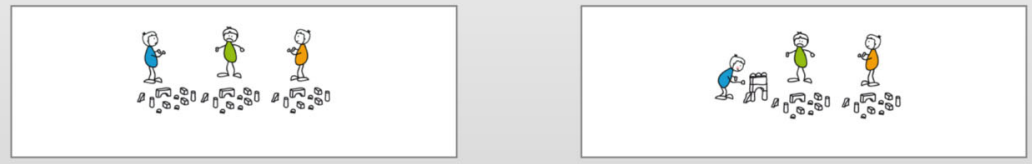

Hurrengo galdera

Fig. 1 Sample screen of the picture selection task for the Basque sequence Inork ezer eraikitzen du (lit. anybody.ERG anything.ABS build.PROG AUX)

performed it (this picture would correspond to a positive reading of the sentence and hence to an existential non-negative interpretation of the indefinite expression). The selection of one picture over the other would reveal the reading that native speakers of Basque associate with sequences that are considered either acceptable or unacceptable depending on the presence of the negative marker and the syntactic order, and thus allow us to (dis)confirm our predictions.

Prior to carrying out the experiment, participants received some training that involved watching a tutorial illustrating a Likert Scale and a Picture-matching test, but the examples that were used in the training session were unrelated to the items used in the actual experimental task. For each of the experimental stimuli, participants had to perform the two tasks just described. Both tasks required a mouse click (first on the Likert Scale numbers, then on one of the two pictures). Once the choice was made, participants could not change their decision.

A sample screen for the picture-matching task is shown in Fig. 1, where the picture on the left represents none of the individuals performing an action (the single negation reading corresponding to the English sentence Nobody is building anything), while the one on the right represents one of the individuals performing it (the existential interpretation of the $i$-/bat ere-indefinite corresponding to the sentence Someone is building something). Note that the sentence in Fig. 1 is expected to be ungrammatical in Basque according to descriptive studies (Etxepare 2003), as $i$ - indefinites must always co-occur with an overt negative licensor, $e z$ 'not'.

The experiment was conducted by means of the open access LingMarket application that was designed for data gathering by Etxeberria et al. (2013) (available at https://isqi.iker.univ-pau.fr/, last accessed 28 March 2021). All the items were pseudo-randomized via the LingMarket application. The 144 items of the experiment were divided into three blocks: (1) criticals (48 items); (2) controls (24 items); and (3) fillers (72 items). The items in each block were randomized (group-internal randomization of items), but the LingMarket application also incorporates a pseudorandomization system that guarantees two critical items (belonging or not to the same condition) would not appear consecutively (to avoid, for example, having a critical sentence with the sentential negative marker being followed by a sentence with the 
same elements but without the sentential negative marker) and also that each participant would view the test items in a different order.

Furthermore, by applying left-right picture randomization we avoided a potential Spatial-Numerical Association of Response Codes (SNARC) effect that may derive from the experience of reading from left to right (Dehaene et al. 1993; Fischer 2003, and others).

\subsubsection{Participants}

20 native speakers of Central Basque (14 women and 6 men, Mage $=42.10, \mathrm{SD}=$ 3.39) completed the experiment. Prior to enrollment, as a pre-condition to participate in the experiment, all participants needed to register in the LingMarket online application where they were also asked to fill a short questionnaire about their proficiency in Basque. This questionnaire confirmed that they had a command of Basque equivalent to at least a Common European Framework of Reference level C1. Moreover, all participants were asked to answer a brief sociolinguistic questionnaire at the end of the experiment in which they were asked about their gender, age, place of birth and location, and their daily percentage of use of their native language. All participants were native speakers of the central variety of Basque, and had a percentage of daily use of Basque of $75 \%$ or above. ${ }^{9}$ All speakers were Basque-Spanish bilinguals. (See the table of demographic information in Appendix 1 of the Supplementary Online data).

\subsubsection{Materials}

The experiment consisted of 72 Basque transitive stimuli subdivided into 6 conditions: 4 critical conditions and 2 control conditions. Critical conditions aimed at investigating the speakers' judgements in acceptability and interpretation of sequences with different degrees of complexity in subject and in object position. Control conditions aimed at establishing the speakers' capacity to attribute existential readings to affirmative sentences containing indefinite nominal expressions.

In critical stimuli, simple pronominal indefinites ( $i$ - indefinites) were combined with complex indefinite DPs (bat ere- indefinites with partitive complements) resulting in four syntactic patterns: DP-DP, Pro-Pro, Pro-DP, and DP-Pro (Déprez et al. 2015). ${ }^{10}$ Indefinite expressions occurred in subject and object position, respectively. We aimed to test whether the different complexity of either the subject or the object of the sentence had any effect on the acceptability and interpretation of the critical items. As the presence or absence of the sentential negative marker was a factor, for each critical condition 6 out of the 12 tokens contained $e z$ and 6 did not. Thus, we created a factorial design that allowed us to isolate the factors that in the critical conditions could give rise to relative differences in acceptability, namely the presence vs. absence of the negative marker, and simple/complex indefinites.

\footnotetext{
${ }^{9}$ None of the participants belonged to the Navarro-Labourdin Basque dialect (see fn. 5). We did not consider young generations that could accept $i$ - indefinites as fragment answers (see fn. 4) either.

${ }^{10}$ The DP-DP condition had multiple bat ere indefinites, the Pro-Pro condition had multiple $i$ - indefinites, and conditions Pro-DP and DP-Pro had both types (i.e. bat ere indefinites and $i$ - indefinites) in different subject/object positions.
} 
In control stimuli, two different conditions were investigated: (i) simple bat 'one' indefinite with no partitive complement either in subject or in object position, or in both (labeled as Existential_bat_Subject_Object_Position); and (ii) norbait 'someone'/zerbait 'something' indefinites either in subject or in object position (labeled as Existential_norbait/zerbait_Subject_Object_Position).

There were 12 tokens per condition, thus yielding a total of 48 critical items and 24 control items.

A total of 72 filler sentences were used as distractors. These sentences were either transitive or intransitive. Some of them were affirmative, while others were negative. While most of them contained just one simple clause, others contained a combination of a main clause plus a subordinate clause, so that the different complexity of critical stimuli had a parallel among filler sentences.

The distribution of stimuli is summarized and exemplified in Table 1. (See the whole set of materials in Appendix 2 of the Supplementary Online data.)

\subsubsection{Procedure and analysis}

Participants completed the tasks on an individual computer in a quiet room at the Center IKER in Bayonne. The test was administered individually. No corrections were allowed. Each experiment lasted between 30 and 40 minutes.

The participants' scores given in the 1-to-5 Likert Scale used to measure acceptability are reported here transformed into a 0-to- 1 scale to provide a clearer account of participants' acceptance rate. The mean existential interpretation for critical and control stimuli is also given in a 0 -to- 1 scale $(0$ corresponding to a negative reading for the sentence and 1 to an existential reading).

All the data obtained were analyzed through linear mixed-effects regressions using the glmmTMB package in R. Regarding the specification of the random effects structure, a series of models were computed, from models including multiple random slopes by participant plus a random intercept for item, to a model including just a random intercept for participant. All converging models were compared using the package performance, by which the model that best fitted the data was selected in any case. The use of mixed-effects models allowed us to include random factors for participants and items when relevant, so that their variation could be appropriately modeled (Baayen et al. 2008; Jaeger 2008; Barr et al. 2013). The omnibus test results of the model were also extracted by using the Anova function of the car package applied to the glmmTMB models, and pairwise contrasts were calculated by using the emmeans package.

\section{Results}

\subsection{Acceptability judgement task}

Figure 2 presents the results of the acceptability judgement task. As shown in the figure, critical stimuli with an overt negative marker (light grey) were rated as significantly more acceptable than critical stimuli without it (dark grey), thus confirming 
Table 1 Patterns for critical, control conditions and fillers ${ }^{\mathrm{a}}$

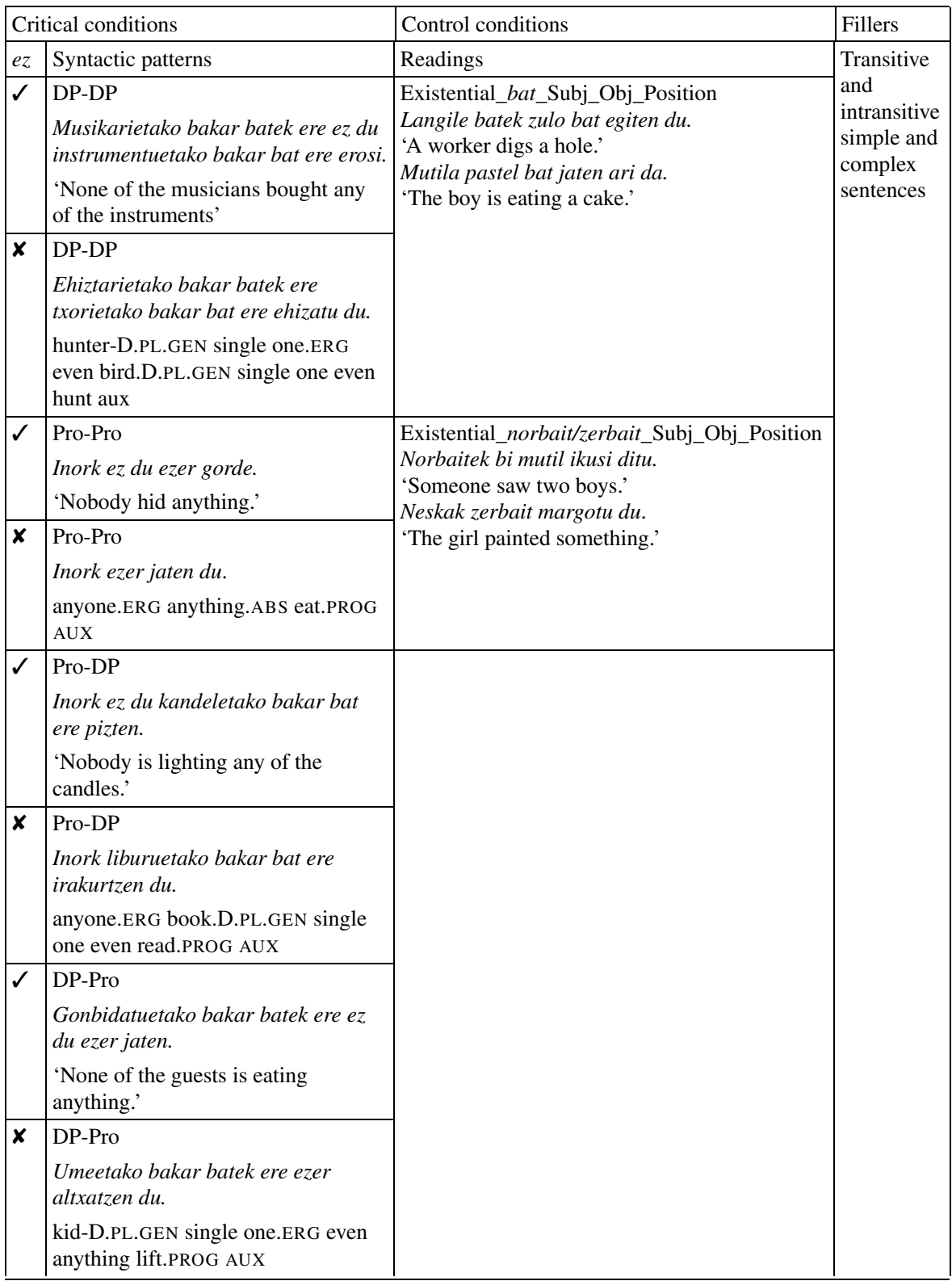

${ }^{a}$ For simplicity, in Table 1 a translation has been provided for the grammatical stimuli, whereas a wordby-word gloss has been included for the ungrammatical ones

our prediction that $i$-/bat ere- indefinites without a negative licensor should receive low acceptability ratings. It can also be observed that the Pro-Pro condition $(i$ - indefinites such as inor 'anybody', ezer 'anything', in subject and object position) with a 


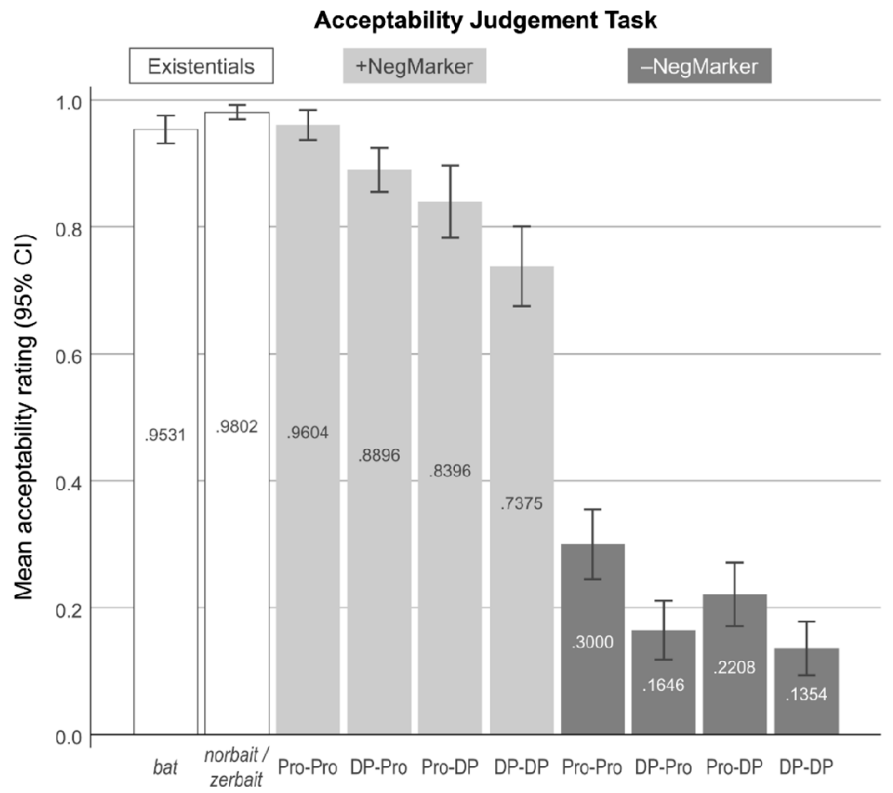

Fig. 2 Mean acceptability ratings for control (Existentials) and critical ( \pm NegMarker) stimuli

negative marker (i.e. sentences with two $i$ - indefinites with $e z$ ) is the one that receives the highest acceptability ratings (comparable to control stimuli, which, as expected, were considered acceptable almost $100 \%$ of the time), while the DP-DP condition (bat ere- indefinites in subject and object position) with a negative marker (i.e. two bat ere-indefinites with $e z$ ) is assigned lower acceptability ratings than the rest of the critical stimuli with $e z$ and the two control conditions. This graph also shows that, among the conditions without the negative marker, Pro-Pro is the condition considered most acceptable, while DP-DP is the least acceptable one, which suggests that the Pro/DP complexity plays a role in this acceptability judgement task.

The answers to the Likert Scale test were analyzed by means of a linear mixedeffects model, taking the 0 -to-1 response values as the dependent variable. NegMarker [overt, covert], SubjectComplexity [Pro, DP], ObjectComplexity [Pro, DP], and all their possible interactions were set as fixed factors. A random slope for both NegMarker and ObjectComplexity by participant was included in the model. The intercept was set to NegMarker [overt], SubjectComplexity [Pro], and ObjectComplexity [Pro] $(B=0.96, S E=0.03, \beta=1.01, z=14.95, p<.001)$.

A significant effect was found between the intercept and the following three predictors: NegMarker [covert], $B=-0.66, S E=0.05, \beta=-1.55, z=-12.77$, $p<.001$, SubjectComplexity [DP], $B=-0.07, S E=0.02, \beta=-0.17, z=-2.95$, $p=.003$, and ObjectComplexity [DP], $B=-0.12, S E=0.04, \beta=-0.28, z=$ $-3.43, p=.001$. This indicates that Pro-Pro structures with an overt negative marker were more accepted than those varying in the three main factors under study (i.e., the intercept [overt Pro-Pro] was found to be statistically different, respectively, from [covert Pro-Pro], [overt DP-Pro], and [overt Pro-DP]). In line with this, the omnibus test indicated that the three main effects were found to be significant: NegMarker, 
$\chi^{2}(1)=189.400, p<.001$, indicating that sentences with $e z$ were more accepted than those without it $(d=3.51, p<.001)$; SubjectComplexity, $\chi^{2}(1)=67.324$, $p<.001$, indicating that structures with a Pro subject were more accepted than those with a DP subject $(d=0.53, p<.001)$; and ObjectComplexity, $\chi^{2}(1)=11.258$, $p=.001$, indicating that sentences with a Pro object were more accepted than those with a DP object $(d=0.51, p=.001)$. In addition, a significant interaction was found for NegMarker $\times$ ObjectComplexity, $\chi^{2}(1)=11.762, p=.001$, which can be interpreted such that sentences with a Pro object were significantly more accepted than those with a DP object when the negative marker was overt $(d=0.73, p<.001)$, but not when covert $(d=0.29, p=.079)$. All in all, the statistical results indicate a main difference regarding the presence or absence of the negative marker, and a slightly different role of constituent complexity within these two possibilities. On the one hand, in sentences including an overt $e z$, a preference is found such that Pro-Pro $>$ DP-Pro $>$ Pro-DP > DP-DP (cf. Fig. 2); i.e., participants prefer sentences with Pro constituents, especially in object position. On the other hand, in sentences without the negative marker, a preference is found such that Pro-Pro $>$ Pro-DP $>$ DP-Pro $>$ DP-DP; i.e., participants prefer sentences with a Pro subject, and, among these, those including a Pro object.

\subsection{Picture selection task}

Figure 3 presents the results of the picture selection task. As can be seen in the graph, critical stimuli with an overt negative marker (light grey) were interpreted as conveying single negation readings. By contrast, critical stimuli without a negative licensor (dark grey) are interpreted with an existential reading almost $100 \%$ of the time. This confirms our second prediction, namely that $i$-lbat ere indefinites are consistently and unambiguously interpreted as conveying an existential reading (exactly as in the two controls) in the absence of a negative licensor.

The answers to the picture selection task were analyzed by using a generalized linear mixed-effects model, taking the choice of the expected picture as the dependent variable ( 0 for the wrong selection, and 1 for the correct selection; Binomial distribution, Logit link). NegMarker [overt, covert], SubjectComplexity [Pro, DP], ObjectComplexity [Pro, DP], and all their possible interactions were set as fixed factors. A random slope for NegMarker by subject plus a random intercept for item were included in the model. The intercept was set again to NegMarker [overt], SubjectComplexity [Pro], and ObjectComplexity [Pro] (odds $=72.05, S E=0.90, \beta=4.28$, $z=4.75, p<.001)$.

The only significant effect found was related to the predictor NegMarker [covert], $o d d s=0.00, S E=1.68, \beta=-9.41, z=-5.60, p<.001$, indicating that the condition with an overt negative marker was less often assigned an existential reading. In line with this, the omnibus test indicated only a main effect for NegMarker, $\chi^{2}(1)=47.813, p<.001$, suggesting that sentences with an overt negative marker were less often assigned an existential reading than those without it $(d=9.23$, $p<.001)$. No relevant effects of constituent complexity are observed along the model. 


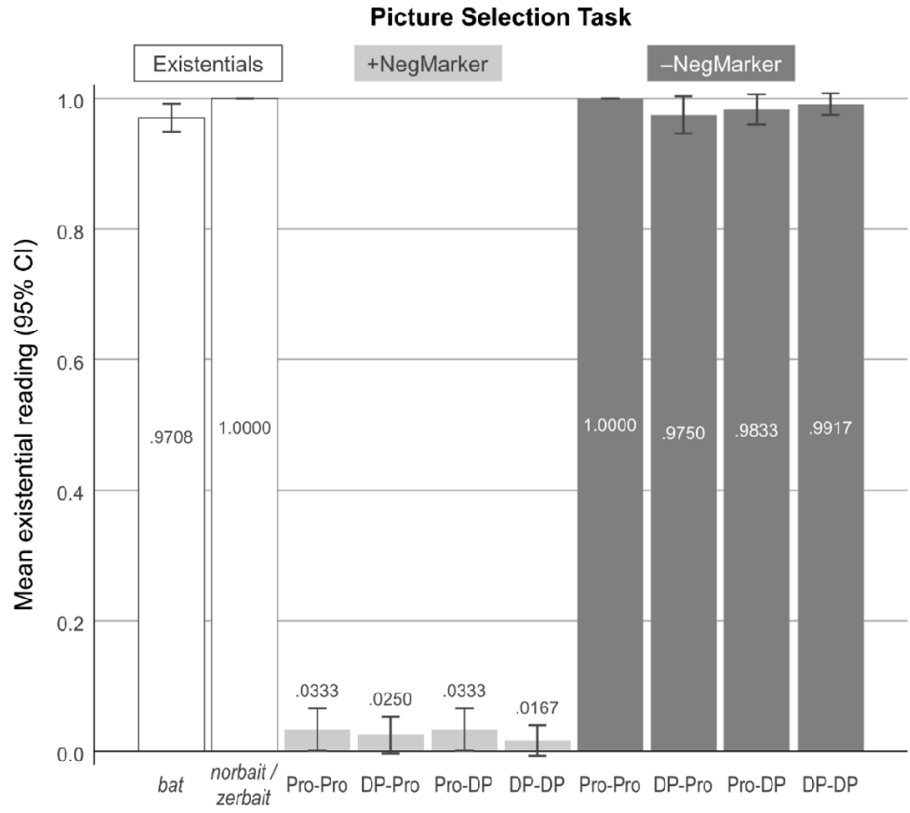

Fig. 3 Mean existential interpretation for control (Existentials) and critical ( \pm NegMarker) stimuli

\section{Discussion and conclusion}

Our results confirm the two predictions presented at the end of Sect. 2. First, when occurring without a negative licensor (i.e., the negative marker), Basque $i$-/bat ere indefinites are given low acceptability ratings. Second, unlicensed $i$-/bat ere indefinites are consistently and unambiguously interpreted existentially (i.e., with a nonnegative reading). These results confirm that $i$-lbat ere indefinites not overtly licensed by a negative marker are interpreted as non-negative in Basque, thus supporting their characterization as PIs. Our results also show that $i$ - indefinites in the Pro-Pro condition behave similarly to bat and norbait/zerbait indefinites when it comes to mean acceptability when occurring with an overt negative marker (see Fig. 2) and mean existential reading in the picture selection task when occurring without it (see Fig. 3), which might be due to the lack of syntactic complexity of the two pronominal indefinites in this critical condition.

Of course, the non-negative existential interpretation that our participants assign to unacceptable critical sentences without an overt negative marker might be conditioned by the syntactic structure, since in the present experiment the word order for sentences without $e z$ was [SOVAUX] — the characteristic word order of affirmative sentences-which might have led participants to choose a non-negative existential interpretation. Crucially, though, our findings can also be argued to constitute a robust argument against Basque $i$-/bat ere indefinites being NCIs. Recall from Sect. 2 that lexical items with a formal feature such as $[u \mathrm{Neg}]$ (Zeijlstra 2004) require such a feature to be checked by means of Agree with a lexical item with an interpretable matching feature. Otherwise, the derivation would crash. It is therefore predicted, in 
the light of current syntactic literature on NC (Zeijlstra 2004, 2008, and ff.; Giannakidou and Zeijlstra 2017), that NCIs are specified with a $[u \mathrm{Neg}]$ feature, and that when they occur in a context without a suitable licensor, such feature triggers the Last Resort insertion of an abstract negative operator that ensures checking of the $[u \mathrm{Neg}]$ feature carried by the NCI. In this situation the presence of an abstract negative operator rules out the possibility of interpreting the NCI with an existential reading. If Basque $i$-lbat ere indefinites were NCIs (and hence specified as $[u \mathrm{Neg}]$ and capable of triggering the insertion of a Last Resort negative operator whenever needed), we would expect critical stimuli sentences without an overt negative marker in our experiment to have been possibly interpreted as conveying single negation. However, our participants consistently interpreted them as having an existential non-negative reading, as shown in Fig. 3.

Additional evidence towards the conclusion that Basque $i$-/bat ere indefinites are PIs but not NCIs comes from a theoretical examination of how similar or different Basque indefinites are from NCIs in a Strict NC language such as Greek. As advanced in Sect. 2, should Basque be considered a NC language, it would have to be classified as Strict NC, for $i$-/bat ere indefinites always occur with the sentential negative marker $e z$ in well-formed negative sentences. Similarly, Modern Greek features NC of the Strict kind (Giannakidou 1998, and ff.), as in this language NCIs need to occur with the negative marker regardless of whether they occur pre- or post-verbally. Modern Greek, therefore, allows us to draw relevant comparisons with Basque that can enlighten the debate on the status of Basque $i$-/bat ere indefinites.

Interestingly, Modern Greek has two series of indefinites: non-emphatic PIs (tipota 'anything', kanenas 'anybody') and emphatic NCIs (TIPOTA 'n-thing', KANENAS 'n-body'). As shown in (15a) and (15b), both PIs (tipota) and NCIs (TIPOTA) can occur post-verbally under the scope of a negative marker (dhen). However, only NCIs (KANENAS) can occur pre-verbally, outscoping the negative marker and licensing post-verbal PIs and NCIs, (15c) and (15d) vs. (15e) and (15f).
a. I Ariadhni dhen ipe tipota. the Ariadhni not said anything 'Ariadhni didn't say anything.'
b. I Ariadhni dhen ipe TIPOTA. the Ariadhni not said n-thing 'Ariadhni didn't say anything.'
c. KANENAS dhen ipe tipota. n-body not said anything 'Nobody said anything.'
d. KANENAS dhen ipe TIPOTA. n-body not said n-thing 'Nobody said anything.'
e. *Kanenas dhen ipe tipota. anybody not said anything
f. *Kanenas dhen ipe TIPOTA. anybody not said $n$-thing

Recall that Basque also has two series of indefinites ( $i$-/bat ere), and we are discussing here whether they should be considered PIs or NCIs. As tempting as it might be to 
conclude, on the basis of the grammaticality of Basque sentences such as (4) and (11b), that Basque $i$-/bat ere indefinites are NCIs - since Greek PIs cannot occur preverbally (15e,f) — other considerations must be taken into account to solve the puzzle.

First, Basque $i$-/bat ere indefinites (like Hindi PIs, Lahiri 1998; but unlike the English PI any) can occur in preverbal position preceding the negative marker, because, we hypothesize, this language does not have another series of items (such as negative quantifiers) for this position. Second, Greek NCIs (unlike Greek PIs and Basque $i$-/bat ere indefinites) can occur as fragment answers without the presence of the negative marker. Third, Greek NCIs (unlike Greek PIs and Basque $i$-/bat ere indefinites), are interpreted negatively when used as fragments to questions (e.g., Ti idhes? TIPOTA 'What did you see? Nothing'; Giannakidou 2000:459, ex. (2)). ${ }^{11}$ This suggests that Greek NCIs require rescue operations that guarantee an Agree relationship between the NCI and a constituent specified with the formal feature [ $i \mathrm{Neg}]$. By contrast, such operations have been empirically shown not to apply in Basque when the negative licensor is not overt and the word order is kept as non-negative. As one of the reviewers has pointed out, Greek has both PIs and NCIs, ${ }^{12}$ other languages (Slavic) appear to have only NCIs, and Basque (like Hindi) only has PIs.

We therefore conclude that Basque $i$-/bat ere indefinites are PIs (hence their consistent interpretation as existentials in unacceptable sentences lacking a negative licensor), but not NCIs, as they do not allow a single negation interpretation in the absence of an overt negative marker. That is, Basque PIs require semantic polarity licensing but not NC, conceived as a syntactic dependency mediated by the operation Agree. Our experimental investigation confirms Laka's (1990) hypothesis that Basque $i$-/bat ere indefinites are PIs, but shows, in addition, that Basque $i$-/bat ere indefinites are not NCIs, and, consequently, that Basque is not a Strict NC language.

Supplementary Information The online version contains supplementary material available at https://doi. org/10.1007/s11049-021-09513-2.

Acknowledgements We would like to express our gratitude to the reviewers as well as to the editor of NLLT for their numerous comments, questions and suggestions. This research has received financial support from the ANR (ANR-17-CE27-11), the ANR-DFG (ANR-18-FRAL-0006), the Netherlands Organisation for Scientific Committee Partitivity in European Languages (PARTE), the Spanish MINECO (FFI2017-82547-P; PGC2018-096380-B-100), and the Generalitat de Catalunya (2017SGR634, and an ICREA Academia awarded to the corresponding author). The experiment was carried out following the regulations of the Ethics Committee on Animal and Human Experimentation of the Universitat Autònoma de Barcelona, under the approved experimental protocol CEEAH - 4442. We thank Olatz Etxeberria for her help with the drawing of the experimental materials, as well as all the participants in this experiment for sharing their judgements with us.

Open Access This article is licensed under a Creative Commons Attribution 4.0 International License, which permits use, sharing, adaptation, distribution and reproduction in any medium or format, as long as

11 Similarly, contrasting with our results from Basque, Greek sequences such as KANENAS ipe tipota/TIPOTA (similar to $(15 \mathrm{c}, \mathrm{d})$, but without the negative marker) are expected to be judged by native speakers as unacceptable (as the licensor for the NCIs is missing), but to be interpreted as negative due to the presence of a Last Resort negative abstract operator triggered by the formal feature [ $u$ Neg]. We leave confirmation of this hypothesis for further research.

12 The same would apply to Spanish, which has PIs (e.g., N alguno 'any N') and NCIs (e.g., nadie 'nobody') (Bosque 1980; Sánchez 1999; Espinal 2000). 
you give appropriate credit to the original author(s) and the source, provide a link to the Creative Commons licence, and indicate if changes were made. The images or other third party material in this article are included in the article's Creative Commons licence, unless indicated otherwise in a credit line to the material. If material is not included in the article's Creative Commons licence and your intended use is not permitted by statutory regulation or exceeds the permitted use, you will need to obtain permission directly from the copyright holder. To view a copy of this licence, visit http://creativecommons.org/licenses/by/ 4.0/.

\section{References}

Atkinson, Emily, Aaron Apple, Kyle Rawlins, and Akira Omaki. 2016. Similarity of wh-phrases and acceptability variation in $w$-Islands. Frontiers in Psychology 6: 2048. https://doi.org/10.3389/fpsyg. 2015.02048.

Baayen, Rolf Harald, Douglas J. Davidson, and Douglas M. Bates. 2008. Mixed-effects modeling with crossed random effects for subjects and items. Journal of Memory and Language 59: 390-412. https:// doi.org/10.1016/j.jml.2007.12.005.

Barr, Dale J., Roger Levy, Christoph Scheepers, and Harry J. Tily. 2013. Random effects structure for confirmatory hypothesis testing: Keep it maximal. Journal of Memory and Language 68: 255-278. https://doi.org/10.1016/j.jml.2012.11.001.

Beltrama, Andrea, and Ming Xiang. 2016. Unacceptable but comprehensible: The facilitation effect of resumptive pronouns. Glossa 1(1): 29. https://doi.org/10.5334/gjgl.24.

Bosque, Ignacio. 1980. Sobre la negación, Madrid: Cátedra.

Christensen, Ken Ramshøj. 2020. The neurology of negation: fMRI, ERP, and aphasia. In The Oxford handbook of negation, eds. Viviane Déprez and M.Teresa Espinal, 725-739. Oxford: Oxford University Press.

de Rijk, Rudolf P. G. 1969. Is Basque an SOV language? Fontes Linguae Vasconum 1: 319-351.

de Rijk, Rudolf P. G. 1972. Studies in Basque syntax: Relative clauses. Ph.D. diss., Massachusetts Institute of Technology.

de Rijk, Rudolf P. G. 1996. Focus and quasifocus on the Basque negative statements. Revista Internacional de Estudios Vascos 41(1): 63-76.

de Rijk, Rudolf P. G. 2008. Standard Basque: A progressive grammar. Cambridge: MIT Press.

Dehaene, Stanislas, Serge Bossini, and Pascal Giraux. 1993. The mental representation of parity and number magnitude. Journal of Experimental Psychology 122(3): 371-396. https://doi.org/10.1037/00963445.122.3.371.

Déprez, Viviane. 1997. Two types of Negative Concord. Probus, International Journal of Romance Linguistics 9: 103-143.

Déprez, Viviane. 2000. Parallel (a)symmetries and the internal structure of negative expressions. Natural Language and Linguistic Theory 18: 253-342.

Déprez, Viviane. 2011. Atoms of negation: An outside-in micro-parametric approach to Negative Concord. In The evolution of negation: beyond the Jespersen cycle, eds. Richard Ingham, and Pierre Larrivée, 221-272. Berlin: Mouton de Gruyter.

Déprez, V. 2018. What is strict negative Concord? Lessons from French based creoles. In Negation and contact: with special focus on Singapore English, eds. Debra Ziegler and Zhiming Bao, 81-114. Amsterdam: John Benjamins.

Déprez, Viviane, and France Martineau. 2004. Micro-parametric variation and negative Concord. In Contemporary approaches to Romance linguistics, eds. Julie Auger, J. Clancy Clements, and Barbara Vance, 139-158. Amsterdam: John Benjamins.

Déprez, Viviane, Susagna Tubau, Anne Cheylus, and M.Teresa Espinal. 2015. Double negation in a negative concord language: An experimental investigation. Lingua 163: 75-107. https://doi.org/10.1016/ j.lingua.2015.05.012.

Duguine, Maia, and Artiz Irurtzun. 2010. Opérateurs d'exclusivité dans les questions et réponses en basque. Revue de Sémantique et Pragmatique 27: 105-116.

Elordieta, Arantzatzu. 2001. Verb movement and constituent permutation in Basque. Ph.D. diss., University of Leiden.

Espinal, M.Teresa. 2000. On the semantic status of n-words in Catalan and Spanish. Lingua 110: 557-580.

Espinal, M.Teresa, and Susagna Tubau. 2016. Interpreting argumental n-words as answers to negative questions. Lingua 177: 41-59. 
Etxeberria, Urtzi, and Aritz Irurtzun. 2015. The emergence of scalar meanings. Frontiers in Psychology 6: 141. https://doi.org/10.3389/fpsyg.2015.00141.

Etxeberria, Urtzi, Aritz Irurtzun, Ion Lizarazu, and Gotzon Santander. 2013. LingMarket: The linguistics data market. UPPA. Available at https://isqi.iker.univ-pau.fr/.

Etxeberria, Urtzi, Susagna Tubau, Viviane Déprez, Joan Borràs-Comes, and M.Teresa Espinal. 2018. Relating (un)acceptability to interpretation. Experimental investigations on negation. Frontiers in Psychology 8, 2370. https://doi.org/10.3389/fpsyg.2017.02370.

Etxepare, Ricardo. 2003. Negation. In A grammar of Basque, eds. José Ignacio Hualde and Jon Ortiz de Urbina, 387-421. Berlin: Mouton de Gruyter.

Etxepare, Ricardo, and Myriam Uribe-Etxebarria. 2008. On negation and focus in Spanish and Basque. In Gramatika jaietan Patxi Goenaga irakaslearen omenaldiz. Special issue of International Journal of Basque Linguistics and Philology, eds. Xabier Artiagoitia and Joseba A. Lakarra, 287-309. Bilbao: $\mathrm{UPV} / \mathrm{EHU}$

Euskaltzaindia. 1993. Euskal Gramatika Laburra: Perpaus Bakuna. Bilbao: Euskaltzaindia.

von Fintel, Kai. 1999. NPI-licensing, Strawson-entailment, and context-dependency. Journal of Semantics 16: 97-148.

Fischer, Martin. 2003. Spatial representations in number processing: Evidence from a pointing task. Visual Cognition 10: 493-508. https://doi.org/10.1080/13506280244000186.

Frazier, Lyn, and Charles Clifton Jr.. 2011. Quantifiers undone: Reversing comprehensible speech errors in comprehension. Language 87: 158-171. https://doi.org/10.1353/lan.2011.0024.

Giannakidou, Anastasia. 1997. The landscape of polarity items. PhD diss., Rijksuniversiteit Groningen.

Giannakidou, Anastasia. 1998. Polarity sensitivity as (non) veridical dependency. Amsterdam: John Benjamins.

Giannakidou, Anastasia. 2000. Negative...concord? Natural Language and Linguistics Theory 18: 457-523. https://doi.org/10.1023/A:1006477315705.

Giannakidou, Anastasia. 2006. N-words and negative concord. In The Blackwell companion to syntax, eds. Martin Everaert and Henk van Riemsdijk. Vol. 3, chapter 45, 327-391. Oxford: Blackwell.

Giannakidou, Anastasia. 2020. Negative concord and the nature of negative concord items. In The $O x$ ford handbook of negation, eds. Viviane Déprez and M.Teresa Espinal, 458-478. Oxford: Oxford University Press.

Giannakidou, Anastasia, and Urtzi Etxeberria. 2018. Assessing the role of experimental evidence for interface judgment: Licensing of negative polarity items, scalar readings, and focus. Frontiers in Psychology 9: 59. https://doi.org/10.3389/fpsyg.2018.00059.

Giannakidou, Anastasia, and Hedde Zeijlstra. 2017. The landscape of negative dependencies: negative concord and n-words. In The Wiley Blackwell companion to syntax 2nd edn., eds. Martin Everaert and Henk van Riemsdijk, 2099-2136. Hoboken: Wiley Blackwell.

Gibson, Edward, Leon Bergen, and Steven T. Piantadosi. 2013. Rational integration of noisy evidence and prior semantic expectations in sentence interpretation. In Proceedings of the National Academy of Sciences of the United States of America 110(20), ed. John R. Anderson, 8051-8056. https://doi.org/ 10.1073/pnas. 1216438110.

Grodzinsky, Yosef, Isabelle Deschamps, Peter Pieperhoff, Francesca Iannilli, Galit Agmon, Yonatan Loewenstein, and Katrin Amunts. 2020a. Logical negation mapped onto the brain. Brain Structure and Function 225: 19-31. https://doi.org/10.1007/s00429-019-01975-w.

Grodzinsky, Yosef, Virginia Jaichenco, Isabelle Deschamps, María Elina Sánchez, Martín Fuchs, Peter Pieperhoff, Yonatan Loewenstein, and Katrin Amunts 2020b. Negation and the brain: Experiments in health and in focal brain disease, and their theoretical implications. In The Oxford handbook of negation, eds. Viviane Déprez and M.Teresa Espinal, 694-712. Oxford: Oxford University Press.

Haegeman, Liliane, and Rafaella Zanuttini. 1991. Negative heads and the neg criterion. The Linguistic Review 8: 233-252.

Herburger, Elena. 2001. The negative concord puzzle revisited. Natural Language Semantics 9: $289-333$.

Ionin, Tania, and Eve Zyzik. 2014. Judgment and interpretation tasks in second language research. Annual Review of Applied Linguistics 34: 37-64. https://doi.org/10.1017/S0267190514000026.

Jaeger, Florian T. 2008. Categorical data analysis: Away from ANOVAs (transformation or not) and towards logit mixed models. Journal of Memory and Language 59: 434-446. https://doi.org/10.1016/j. jml.2007.11.007.

Juzek, Tom S. 2016. Acceptability judgement tasks and grammatical theory. Ph.D. diss., University of Oxford.

Klima, Edward S. 1964. Negation in English. In The structure of language, eds. Jerry A. Fodor and Jerrold J. Katz, 246-323. Englewood Cliffs: Prentice Hall. 
Ladusaw, William. 1979. Negative polarity as inherent scope relations. New York: Garland.

Ladusaw, William. 1992. Expressing negation. In Semantics and Linguistic Theory (SALT) 2, eds. Chris Baker and David Dowty, 237-259. Ohio: Ohio State University.

Ladusaw, William. 1994. Thetic and categorial, stage and individual, weak and strong. In Semantics and Linguistic Theory (SALT) 4, eds. Mandy Harvey and Lynn Santelmann, 220-229. Ithaca: Cornell University.

Lahiri, Utpal. 1998. Focus and negative polarity in Hindi. Natural Language Semantics 6(1): 57-123.

Laka, Itziar. 1990. Negation in syntax: On the nature of functional categories and projections. Ph.D. diss., Massachusetts Institute of Technology.

Martins, Ana Maria. 2000. Polarity items in Romance: Underspecification and lexical change. In $D i$ achronic syntax: Models and mechanisms, eds. Susan Pintzuk, George Tsoulas, and Anthony Warner, 191-219. Oxford: Oxford University Press.

Michelena, Luis. 1985. Lengua e historia. Madrid: Paraninfo.

Muller, Hanna, and Colin Phillips. 2020. Negative polarity illusions. In The Oxford handbook of negation, eds. Viviane Déprez and M.Teresa Espinal, 656-676. Oxford: Oxford University Press.

Pablos Robles, Leticia, Jenny Doetjes, Bobby J. Ruijgrok, and Lisa L. S. Cheng. 2019. Backward licensing of negative polarity items in Dutch: An ERP investigation. Journal of Neurolinguistics 51: 96-110.

Panizza, Daniele, and Jacopo Romoli. 2013. On the processing of alternatives, exhaustification and covert negation: The case of mai. In Alternatives in semantics. Palgrave studies in pragmatics, language and cognition, ed. Anamaria Fălăuş, 209-237. London: Palgrave Macmillan.

Parker, Dan, and Colin Phillips. 2016. Negative polarity illusions and the format of hierarchical encodings in memory. Cognition 157: 321-339.

Phillips, Colin, Matthew W. Wagers, and Ellen F. Lau. 2011. Grammatical illusions and selective fallibility in real-time language comprehension. In Experiments at the interfaces, ed. Jeffrey Runner. Vol. 37 of Syntax and semantics, 153-186. Bingley: Emerald.

Sánchez López, Cristina. 1999. La negación. In Gramática descriptiva de la lengua española, eds. Ignacio Bosque and Violeta Demonte, 2561-2634. Madrid: Espasa-Calpe.

Schütze, Carson T., and Jon Sprouse. 2013. Judgement data. In Research methods in linguistics, eds. Robert J. Podesva and Devyani Sharma, 27-51. Cambridge: Cambridge University Press.

Shanon, Benny. 1973. Interpretation of ungrammatical sentences. Journal of Verbal Learning and Verbal Behaviour 12: 389-400. https://doi.org/10.1016/S0022-5371(73)80017-9.

Suñer, Margarita. 1995. Negative elements, island effects and resumptive no. The Linguistic Review 12: 233-373.

Tonhauser, Judith, and Lisa Matthewson. 2015. Empirical evidence in research on meaning. Ms., Ohio State University and Univ of British Columbia. Available at http://ling.auf.net/lingbuzz/002595.

Tubau, Susagna. 2008. Negative concord in English and Romance: syntax-morphology interface conditions on the expression of negation. PhD diss., UAB.

Vallduví, Enric. 1994. Polarity items, n-words and minimizers in Catalan and Spanish. Probus 6: $263-294$.

Vasishth, Shravan, Sven Brüssow, Richard L. Lewis, and Heiner Drenhaus. 2008. Processing polarity: How the ungrammatical intrudes on the grammatical. Cognitive Science 32: 685-712. https://doi.org/10. 1080/03640210802066865.

Wellwood, Alexis, Roumyana Pancheva, Valentine Hacquard, and Colin Phillips. 2018. The anatomy of a comparative illusion. Journal of Semantics 35(3): 543-583. https://doi.org/10.1093/jos/ffy014.

Zanuttini, Rafaella. 1989. The structure of negative clauses in Romance. Paper presented at 12th annual GLOW colloquium, Utrecht.

Zanuttini, Rafaella. 1991. Syntactic properties of sentential negation. PhD diss., University of Pennsylvania.

Zeijlstra, Hedde. 2004. Sentential negation and negative concord. PhD diss., University of Amsterdam.

Zeijlstra, Hedde. 2008. Negative concord is syntactic agreement. Ms., University of Amsterdam. Available at http://ling.auf.net/lingbuzz/000645/current.pdf.

Zwarts, Frans. 1981. Negatief polaire uitdrukkingen I. GLOT 4(1): 35-133.

Zwarts, Frans. 1995. Nonveridical contexts. Linguistic Analysis 25: 286-312.

Publisher's Note Springer Nature remains neutral with regard to jurisdictional claims in published maps and institutional affiliations. 